\title{
Pengaruh Kualitas Pelayanan, Bauran Pemasaran Dan Citra Merek Terhadap Loyalitas Pelanggan Pada Mcdonald's Di Kota Denpasar
}

\author{
Ni Kadek Sintha Pratiwi ${ }^{1}$ \\ I Wayan Suartina ${ }^{2}$ \\ Ida Ayu Putu Widani Sugianingrat ${ }^{3}$ \\ ${ }^{1,2,3}$ Fakultas Ekonomi, Bisnis, dan Pariwisata Universitas Hindu Indonesia \\ \begin{tabular}{|l|l|l|}
\hline Diterima: 8 Desember 2020 & Direvisi: 10 Desember 2020 & Disetujui: 25 Desember 2020 \\
\hline
\end{tabular}
}

\begin{abstract}
Customer loyalty is a commitment that customers hold deeply to buy the product or service being offered. In order for customers to have high loyalty, a company needs to pay attention to the factors that determine customer loyalty. The purpose of this study was to determine the effect of service quality, marketing mix and brand image on customer loyalty. This research was conducted at McDonald's company in Denpasar City. The number of samples taken was 100 customers, with probability sampling method, especially simple random sampling. Data collection was carried out through interviews, observation, documentation study, literature study and questionnaires. The analysis technique used is multiple linear regression. Based on the analysis, it is found that service quality, marketing mix and brand image simultaneously have a significant effect on customer loyalty. Partially service quality has a significant effect on customer loyalty, marketing mix has a significant effect on customer loyalty, and brand image has a significant effect on customer loyalty.
\end{abstract} Keywords: service quality, marketing mix, brand image

\begin{abstract}
ABSTRAK
Loyalitas pelanggan merupakan komitmen yang dipegang pelanggan bertahan secara mendalam untuk membeli produk atau jasa yang ditawarkan. Agar pelanggan memiliki loyalitas yang tinggi, suatu perusahaan perlu memperhatikan faktor - faktor yang mengetahui loyalitas pelanggan. Tujuan penelitian ini adalah untuk mengetahui pengaruh kualitas pelayanan, bauran pemasaran dan citra merek terhadap loyalitas pelanggan. Penelitian ini dilakukan di Perusahan McDonald's Di Kota Denpasar. Jumlah sampel yang diambil sebanyak 100 orang pelanggan, dengan metode probability sampling, khususnya simple random sampling. Pengumpulan data dilakukan melalui wawancara, observasi, studi dokumentasi, studi pustaka dan kuesioner. Teknik analisis yang digunakan adalah regresi linier berganda. Berdasarkan hasil analisis ditemukan bahwa kualitas pelayanan, bauran pemasaran dan citra merek secara simultan berpengaruh signifikan terhadap loyalitas pelanggan. Secara parsial kualitas pelayanan berpengaruh signifikan terhadap loyalitas pelanggan, bauran pemasaran berpengaruh signifikan terhadap loyalitas pelanggan, dan citra merek berpengaruh signifikan terhadap loyalitas pelanggan.
\end{abstract}

Kata kunci : kulitas pelayanan, bauran pemasaran, citra merek 


\section{PENDAHULUAN}

Perkembangan bisnis di segala bidang pada saat ini semakin berkembang pesat. Hal ini juga terjadi pada bisnis makanan, salah satunya restoran siap saji pada tahun ini diyakini tumbuh $15 \%$, ditopang oleh membaiknya pendapatan masyarakat serta meningkatnya trend bersantap di luar rumah. Banyak kalangan masyarakat menyukai kepraktisan dalam membeli dan mengkonsumsi makanan. Banyaknya bisnis di bidang makanan menuntut perusahaan untuk mampu bersaing demi meningkatkan kualitas pelayanan untuk dapat tetap bertahan dan mampu mengungguli pesaing - pesaingnya, Sehingga mendapatkan posisi terbaik di hati pelanggannya. Perusahaan harus mampu memberikan kualitas pelayanan yang mampu memberikan kepuasan pada pelanggannya, salah satunya dengan berbagai kemudahan dalam memperoleh layanannya, keramahan pegawai dalam melayani pelanggan, serta pelayanan yang cepat. Kualitas makanan juga menjadi tolak ukur yang di nilai oleh pelanggan untuk datang kembali menikmati makanan yang disediakan oleh restoran cepat saji.

Di Kota Denpasar saat ini sudah banyak bisnis makanan yang tersebar di berbagai pusat keramaian salah satunya restoran cepat saji McDonald's. McDonald's adalah restoran cepat saji yang terkenal dengan menu utamanya yaituproduk hamburger, tetapi seiring berjalannya waktu McDonald's juga menawarkan produk ayam crispy, ayam spicy, happy meal, paket panas, nasi uduk McDonald's dan lain sebagainya. McDonald's adalah restoran cepat saji yang sangant familiar di kota denpasar dan saat ini tersebar di beberapa pusat keramaian sebanyak 7 cabang, melalui data yang penulis olah dari google maps, penulis memperoleh data ulasan pelanggan yang telah berkunjung ke masing - masing cabang McDonald's di Denpasar. Adapun data ulasan ditujukkan pada Tabel 1. Pada Tabel 1 dapat dilihat bahwa jumlah ulasan pada tiap cabang McDonald's di Kota Denpasar bervariasi.Dari setiap cabang yang di kunjungi McDonald's sanur memiliki ulasan yang tertinggi sebesar 5,390 dibandingkan dengan cabang lainnya. Hal tersebut di duga dipengaruhi oleh kualitas pelayanan, lokasi, dan citra merek. Sehingga beberapa pelanggan dengan loyal memberikan ulasan guna menarik pelanggan lain untuk berkunjung ke McDonald's sanur.

Tujuan penelitian ini adalah (1) mengetahui pengaruh kualitas pelayanan terhadap loyalitas, (2) mengetahui pengaruh bauran pemasaran terhadap loyalitas, (3) mengetahui pengaruh citra merek terhadap loyalitas, dan (4) mengetahui pengaruh kualitas pelayanan, bauran pemasaran, dan citra merek secara bersama-sama terhadap loyalitas pelanggan McDonlad's di Kota Denpasar. 
Tabel 1. Jumlah Ulasan Pelanggan Yang Berkunjung pada McDonald's di Kota Denpasar per Januari 2020

\begin{tabular}{clc}
\hline No & Cabang McDonald's & Jumlah Ulasan \\
\hline 1 & McDonald's Nangka & 2,836 \\
2 & McDonald's Ramayana & 2,397 \\
3 & McDonald's Sanur & 5,390 \\
4 & McDonald's Kebo Iwa & 4,654 \\
5 & McDonald's Cokroaminoto & 1,782 \\
6 & McDonald's Teuku Umar Barat & 3,935 \\
7 & McDonald's Sesetan & 1,706 \\
& Total & $\mathbf{2 2 , 7 0 0}$
\end{tabular}

\section{TELAAH LITERATUR DAN HIPOTESIS}

\section{Kualitas Pelayanan}

Menurut Kotler dan Keller (2012: 214) kualitas pelayanan adalah "any act or performance that oneparty can offer another that is essensially intangible and does not not result in the ownership of anything. It "s production may or not be tied to a physical product" artinya setiap tindakan atau kinerja yang satu pihak dapat menawarkan yang lain yang secara esensial tidak berwujud dan tidak menghasilkan kepemilikan apa pun. Menurut (Tjiptono, 2006:12) Kualitas pelayanan adalah keseluruhan ciri-ciri dan karakteristik-karakteristik dari suatu produk atau jasa dalam hal kemampuannya untuk memenuhi kebutuhan-kebutuhan yang telah ditentukan atau bersifat laten, dengan menekankan pada orientasi pemenuhan harapan pelanggan untuk memperoleh kecocokan untuk pemakaian (fitness for use)",

\section{Bauran Pemasaran}

Menurut Kotler dan Amstrong (2012: 75) "marketing mix is the set of tactical marketing tools that the firm blends to produce the response it wants in the target market."Artinya bauran pemasaran adalah seperangkat alat pemasaran taktis yang dipadukan perusahaan untuk menghasilkan respons yang diinginkan di pasar sasaran. Menurut Fandy Tjipto (2011) Marketing mix atau bauran pemasaran adalah kombinasi dari empat variabel yaitu produk, struktur harga, kegiatan promosi, dan sistem distribusi merumuskan bauran pemasaran menjadi 4P (Product, Price, Place dan Promotion).

\section{Citra Merek}

Menurut Kotler dan Keller (2012:248) "Brand Imagery describes the extrinsic properties of the product or service, including the ways in which the brand attempts to meet 
customers psychological or social needs". Brand Image menggambarkan sifat ekstrinsik dari suatu produk atau jasa termasuk cara dimana merek berusaha memenuhi kebutuhan psikologis atau sosial pelanggan. Menurut Kotler dan Armstrong (2013:233) mengemukakan pengertian citra merek "The set of belief held about a particular brand is known as brand image”. Yang artinya adalah sekumpulan keyakinan terhadap suatu merek disebut citra merek

\section{Loyalityas Pelanggan}

Menurut Hurriyati (2010) loyalitas pelanggan adalah komitmen pelanggan bertahan secara mendalam untuk berlangganan kembali atau melakukan pembelian ulang produk/jasa terpilih secara konsisten di masa yang akan datang, meskipun pengaruh situasi dan usahausaha pemasaran mempunyai potensi untuk menyebabkan perubahan perilaku. Menurut Griffin dalam Yovita (2008) Pelanggan (customer) berbeda dengan konsumen (consumen), seorang dapat dikatakan sebagai pelanggan apabila orang tersebut mulai membiasakan diri untuk membeli produk atau jasa yang ditawarkan oleh badan usaha

\section{Hipotesis}

Hipotesis yang diajukan dalam penelitian ini adalah sebagai berikut :

1. Pengaruh kulitas pelayanan terhadap loyalitas pelanggan.

Pelayanan sebagai jasa atau servis yang disampaikan oleh pemilik jasa yang berupa kemudahan, kecepatan, hubungan, kemampuan dan keramah-tamahan yang ditujukan melalui sikap dan sifat dalam memberikan pelayanan untuk kepuasan konsumen (Firdian, dkk., 2012:52). Pernyataan tersebut juga di dukung oleh penelitian Desi Ambar Ayu (2017) yang menunjukan adanya pengaruh positif dan signifikan antara Kualitas pelayanan dengan loyalitas. pelanggan kartu GSM IM3.

H1 : kualitas pelayanan berpengaruh positif dan signifikan terhadap loyalitas pelanggan pada McDonald's di Kota Denpasar.

2. Pengaruh bauran pemasaran terhadap loyalitas pelanggan.

Bauran pemasaran terdiri dari suatu produk, ditawarkan pada harga tertentu, dengan sejenis promosi untuk memberi tahu calon konsumen mengenai produk tersebut, dan suatu cara untuk mencapai tempat konsumen (Cannon,dkk, 2001:41). Pernyataan tersebut juga di dukung oleh penelitian Yusriadi (2018) yang menunjukan adanya pengaruh positif dan signifikan antara bauran pemasaran dengan loyalitas konsumen pada restoran cepat saji O'chicken di Pekanbaru. 
H2 : bauran pemasaran berpengaru hpositif dan signifikan terhadap loyalitas pelanggan.

3. Pengaruh citra merek terhadap loyalitas pelanggan.

Menurut Kotler dan Keller (2009:332) mendefinisikan citra merek adalah suatu kesan yang ada di dalam benak konsumen mengenai suatu merek yang hal ini dibentuk oleh pesan dan pengalaman konsumen mengenai merek, sehingga menimbulkan citra yang ada dalam benak konsumen. Pernyataan tersebut juga di dukung oleh penelitian Abdul Muzammil dkk (2017) yang menunjukan adanya pengaruh positif dan signifikan antara citra merek dengan loyalitas pelanggan pada PT. Telkom Indonesia di Banda Aceh.

H3 : citra merek berpengaruh positif dan signifikan terhadap loyalitas pelanggan.

H4 : kualitas pelayanan, bauran pemasaran, dan citra merek berpengaruh positif dan signifikan terhadap loyalitas pelanggan.

\section{METODE PENELITIAN}

\section{Desain Penelitian}

Berdasarkan penelusuran teori dan pelaksanaan hasil penelitian sebelumnya, dapat digambarkan kerangka berpikir sebagai berikut :

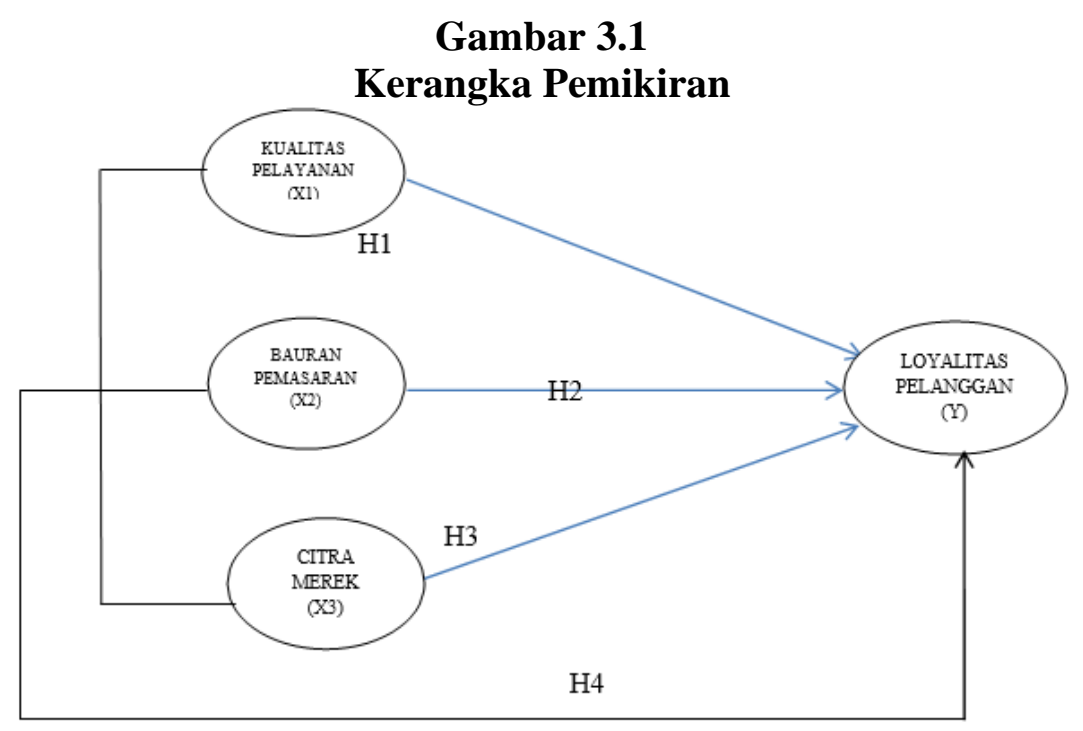

\section{Populasi dan sampel}

Dalam penelitian ini populasi yang dimaksud adalah pelanggan McDonald's di Kota Denpasar. Jumlah pelanggan McDonald's di Kota Denpasar 22.700 orang (McDonald's Denpasar, 2019). Dalam penelitian ini anggota sampel adalah pelanggan McDonald's yang berada di Kota Denpasar dari 7 Outlet.Jumlah sampel yang diambil dalam penelitian ini 
sebanyak 100 responden.Sampel dalam penelitian ini ditentukan dengan menggunakan rumus Solvin. Pengambilan sampel dilakukan dengan metode sampling insidental

\section{Metode Pengumpulan Data}

Pengumpulan data dalam penelitian ini dilakukan dnegan menggunakan berbagai metode yaitu observasi, wawancara, studi dokumentasi, studi pustaka, dan kuisioner. Untuk mendapatkan gambaran respon dari responden terkait variabel yang diteliti, maka kuisioner menggunakan Skala Likert dengan lima pilihan jawaban yaitu sangat tidak setuju diberi nilai 1, tidak setuju diberi nilai 2, cukup setuju diberi nilai 3, setuju diberi nilai 4, dan sangat setuju diberi nilai 5 .

\section{Teknik Analisis Data}

1. Uji instrumen penelitian, terdiri atas uji validitas yang digunakan untuk mengukur sah atau valid tidaknya suatu kuesioner dan Uji reliabilitas digunakan untuk mengukur handal atau tidaknya suatu kuesioner. Kuesioner dikatakan reliable atau tidak jika jawaban dari seseorang terhadap pemyataan adalah konsisten atau stabil dari waktu ke waktu (Ghozali, 2016 : 47-48).

2. Uji asumsi klasik, yang terdiri atas (a) uji normalitas normalitas, (b) uji multikolinearitas, dan (c) uji heteroskedastisitas.

3. Analisis regresi linear berganda. Uji ini dilakukan untuk menjawab hipotesis penelitian yang telah diajukan sebelumnya dengan melakukan uji parsial untuk menjawab H1, H2, dan H3, serta F-tes untuk menjawab H4.

\section{HASIL DAN PEMBAHASAN}

\section{Uji Instrumen Penelitian}

\section{Uji Validitas}

Berdasarkan Tabel 2, diketahui bahwa semua variabel Kualitas Pelayanan mempunyai nilai korelasi lebih besar dari 0.30. Dengan demikian dapat disimpulkan item pernyataan untuk atribut variabel $\mathrm{X}_{1}$ adalah Valid. 
Tabel 2.Hasil Uji Validitas Kualitas pelayanan $\left(\mathrm{X}_{1}\right)$

\begin{tabular}{ccc}
\hline Variable & Pearson correlations $>\mathbf{0 . 3 0}$ & Keterangan \\
\hline $\mathrm{X} 1.1$ & 0.604 & VALID \\
$\mathrm{X} 1.2$ & 0.774 & VALID \\
$\mathrm{X} 1.3$ & 0.759 & VALID \\
$\mathrm{X} 1.4$ & 0.816 & VALID \\
$\mathrm{X} 1.5$ & 0.797 & VALID \\
\hline
\end{tabular}

Sumber : Data primer yang diolah, 2020

Berdasarkan Tabel 3, dapat diketahui bahwa semua variabel Bauran Pemasaran mempunyai nilai korelasi lebih besar dari 0.30 . Dengan demikian dapat disimpulkan item pernyataan untuk atribut variabel $\mathrm{X}_{2}$ adalah Valid.

Tabel 3.Hasil Uji Validitas Bauran Pemasaran $\left(\mathbf{X}_{2}\right)$

\begin{tabular}{ccc}
\hline Variable & Pearson correlations $>\mathbf{0 . 3 0}$ & Keterangan \\
\hline X2.1 & 0.825 & VALID \\
X2.2 & 0.795 & VALID \\
X2.3 & 0.811 & VALID \\
X2.4 & 0.713 & VALID \\
\hline
\end{tabular}

Sumber : Data primer diolah, 2020

Tabel 4 menunjukkan bahwa semua variabel Citra Merek mempunyai nilai korelasi lebih besar dari 0.30. Dengan demikian dapat disimpulkan item pernyataan untuk atribut variabel $\mathrm{X}_{3}$ adalah Valid.

Tabel 4.Hasil Uji Validitas Citra Merek $\left(\mathrm{X}_{3}\right)$

\begin{tabular}{ccc}
\hline Variable & Pearson correlations $>\mathbf{0 . 3 0}$ & Keterangan \\
\hline X2.1 & 0.710 & VALID \\
X2.2 & 0.831 & VALID \\
X2.3 & 0.797 & VALID \\
\hline
\end{tabular}

Sumber : Data primer diolah, 2020

Berdasarkan Tabel 5 diketahui bahwa semua variabel Loyalitas Pelanggan mempunyai nilai korelasi lebih besar dari 0.30. Dengan demikian dapat disimpulkan item pernyataan untuk atribut variabel Y adalah Valid. 
Tabel 5. Hasil Uji Validitas Loyalitas Pelanggan (Y)

\begin{tabular}{ccc}
\hline Variable & Pearson correlations $\boldsymbol{>} \mathbf{0 . 3 0}$ & Keterangan \\
\hline Y1 & 0.565 & VALID \\
Y2 & 0.747 & VALID \\
Y3 & 0.746 & VALID \\
Y4 & 0.565 & VALID \\
Y5 & 0.734 & VALID \\
\hline Sumber : Data primer yang diolah, 2020
\end{tabular}

\section{Uji Reliabilitas}

Berdasarkan tabel 6 dapat dilihat bahwa nilai cronbach alpha variabel Kualitas Pelayanan (0.805), Bauran Pemasaran (0.790), Citra Merek (0.676) dan Loyalitas Pelanggan (0.700) dimana nilai tersebut diatas 0.60. Jadi kesimpulannya untuk variabel Kualitas Pelayanan $\left(\mathrm{X}_{1}\right)$, Bauran Pemasaran $\left(\mathrm{X}_{2}\right)$, Citra Merek $\left(\mathrm{X}_{3}\right)$ dan Loyalitas Pelanggan (Y) adalah Reliabel.

Tabel 6.Hasil Pengujian Reliabilitas

\begin{tabular}{ccc}
\hline Variabel & $\begin{array}{c}\text { Cronbach Alpha } \\
(\boldsymbol{\alpha})>\mathbf{0 . 6 0}\end{array}$ & Keterangan \\
\hline Kualitas Pelayanan & 0.805 & Reliabel \\
Bauran Pemasaran & 0.790 & Reliabel \\
Citra Merek & 0.676 & Reliabel \\
Loyalitas Pelanggan & 0.700 & Reliabel \\
\hline
\end{tabular}

Sumber : data primer, diolah (2020)

\section{Karakteristik Responden}

Berdasarkan Tabel 7 diketahui bahwa dari segi jenis kelamin responden terbanyak adalah perempuan yaitu sebanyak 55 orang atau 55\% dibandingkan laki-laki sebanyak 45 orang atau $45 \%$.

Tabel 7.Jenis Kelamin Responden

\begin{tabular}{ccc}
\hline Jenis Kelamin & Frekuensi (orang) & Persentase \% \\
\hline Laki-laki & 45 & $45 \%$ \\
Perempuan & 55 & $55 \%$ \\
jumlah & $\mathbf{1 0 0}$ & $\mathbf{1 0 0} \%$ \\
\hline Sumber : Data primer yang diolah, 2020
\end{tabular}


Berdasarkan Tabel 8 dapat di lihat bahwa responden yang berusia $<20$ tahun sebanyak 55 orang atau 55\% dikarenakan pelanggan milenial lebih banyak melakukan pembelian produk dan digunakan sebagai tempat untuk kumpul, 20-30 tahun sebanyak 25 orang atau 25\%, responden yang berusia 31-40 tahun sebanyak 15 orang atau $15 \%$ dan responden yang berusia 41-50 tahun sebanyak 5 orang atau 5\% yang berkunjung ke McDonald's di Denpasar.

Tabel 8.Persentase Umur Responden

\begin{tabular}{ccc}
\hline Umur & Frekuensi (orang) & Persentase \\
\hline$<20$ & 55 & $55 \%$ \\
$20-30$ & 25 & $25 \%$ \\
$31-40$ & 15 & $15 \%$ \\
$41-50$ & 5 & $5 \%$ \\
Jumlah & $\mathbf{1 0 0}$ & $\mathbf{1 0 0} \%$ \\
\hline
\end{tabular}

Sumber : Data primer yang diolah, 2020

Dilihat pada Tabel 8 pekerjaan saat ini yang dimiliki para responden terdiri dari 9 orang atau 9\% sebagai PNS, 11 orang atau $11 \%$ sebagai BUMN, 13 orang atau $13 \%$ sebagai karyawan swasta dan 67 orang atau $67 \%$ sebagai pelajar/mahasiswa.

Tabel 9.Persentase Pekerjaan Responden

\begin{tabular}{ccc}
\hline Pekerjaan saat ini & Frekuensi (orang) & $\begin{array}{c}\text { Persentase } \\
\text { \% }\end{array}$ \\
\hline PNS & 9 & $9 \%$ \\
BUMN & 11 & $11 \%$ \\
Karyawan Swasta & 13 & $13 \%$ \\
Pelajar/mahasiswa & 67 & $67 \%$ \\
Jumlah & $\mathbf{1 0 0}$ & $\mathbf{1 0 0} \%$ \\
\hline
\end{tabular}

Sumber : Data primer yang diolah, 2020

Dilihat pada Tabel 9 frekuensi kunjungan sebanyak 2-3 kali para responden terdiri dari 65 orang atau 65\%, sebanyak 3-4 kali terdiri dari 20 orang atau 20\%, dan sebanyak lebih dari 4 kali/bln terdiri dari 15 orang atau $15 \%$. 
Tabel 9.Persentase Frekuensi Kunjungan Responden

\begin{tabular}{ccc}
\hline Kunjungan & Frekuensi (orang) & Persentase \% \\
\hline $2-3 \mathrm{kali}$ & 65 & $65 \%$ \\
3 - 4 kali & 20 & $20 \%$ \\
Lebih dari 4 kali/bln & 15 & $15 \%$ \\
Jumlah & $\mathbf{1 0 0}$ & $\mathbf{1 0 0 \%}$ \\
\hline
\end{tabular}

Sumber : Data primer yang diolah, 2020

\section{Deskripsi Variabel Penelitian}

Data pada Tabel 10 menunjukkan bahwa jawaban responden mengenai kualitas pelayanan memperoleh nilai rata-rata sebesar 4.20 dan masuk dalam kriteria baik. Hal tersebut menunjukkan bahwa kualitas pelayanan di McDonald's diterapkan dengan baik. Nilai rata-rata tertinggi jawaban responden ditunjukkan pada pernyataan "Fasilitas fisik yang disediakan oleh McDonald's sangat bagus" sebesar 4.50. selanjutnya nilai rata-rata terendah jawaban responden ditunjukkan pada pernyataan "Karyawan McDonald's cepat membantu pelanggan McDonald's dalam memberikan pelayanan" dengan nilai rata-rata sebesar 4.08 .

Tabel 10.Jawaban Responden mengenai Kualitas Pelayanan

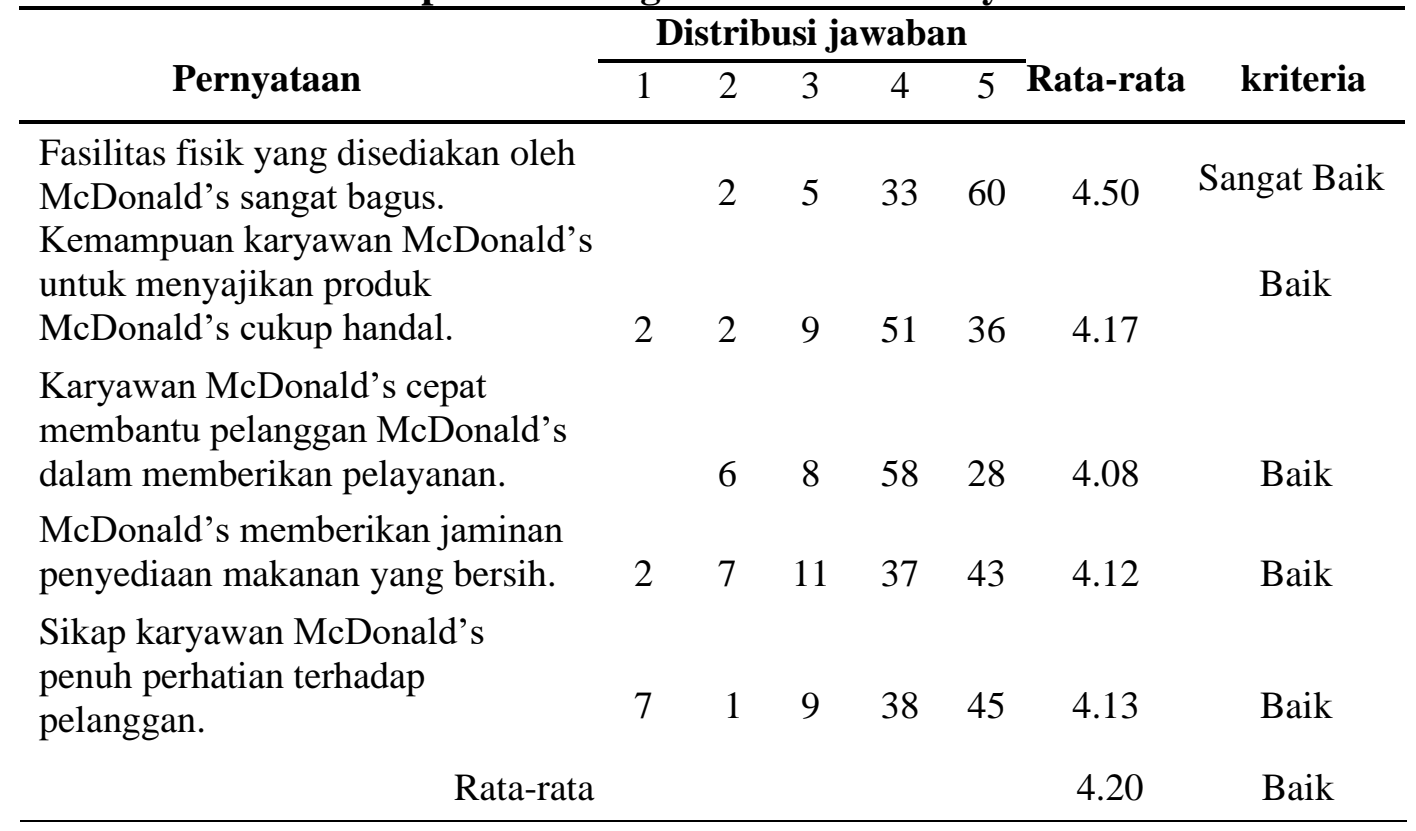

Sumber : Data primer yang diolah, 2020

Data pada Tabel 11 menunjukkan bahwa jawaban responden mengenai bauran pemasaran memperoleh nilai rata-rata sebesar 4.05 dan masuk dalam kriteria baik. Hal tersebut menunjukkan bahwa bauran pemasaran McDonald's diterapkan dengan baik. Nilai rata-rata tertinggi jawaban responden ditunjukkan pada pernyataan ” Lokasi McDonald's 
sangat strategis" sebesar 4.23.

Tabel 11.Jawaban Responden mengenai Bauran Pemasaran

\begin{tabular}{|c|c|c|c|c|c|c|c|}
\hline \multirow[b]{2}{*}{ Pernyataan } & \multicolumn{5}{|c|}{ Distribusi jawaban } & \multirow[b]{2}{*}{ Rata-rata } & \multirow[b]{2}{*}{ Ket } \\
\hline & 1 & 2 & 3 & 4 & 5 & & \\
\hline $\begin{array}{l}\text { Produk Mcdonald's diminati } \\
\text { berbagai kalangan masyarakat. }\end{array}$ & 3 & 3 & 10 & 46 & 38 & 4.13 & Baik \\
\hline $\begin{array}{l}\text { Harga produk McDonald's } \\
\text { cukup terjangkau bagi } \\
\text { masyarakat. }\end{array}$ & 1 & 5 & 16 & 50 & 28 & 3.99 & Baik \\
\hline $\begin{array}{l}\text { Lokasi McDonald's sangat } \\
\text { strategis. }\end{array}$ & & 3 & 13 & 42 & 42 & 4.23 & $\begin{array}{l}\text { Sangat } \\
\text { Baik }\end{array}$ \\
\hline $\begin{array}{l}\text { Mcdonald's sering memberikan } \\
\text { promo bagi pelanggannya. }\end{array}$ & 4 & 4 & 14 & 56 & 22 & 3.88 & Baik \\
\hline Rata - rata & & & & & & 4.05 & Baik \\
\hline
\end{tabular}

Data pada Tabel 12 menunjukkan bahwa jawaban responden mengenai citra merek memperoleh nilai rata-rata sebesar 4.33 dan masuk dalam kriteria sangat baik. Hal tersebut menunjukkan bahwa citra merek McDonald's diterapkan dengan baik. Nilai rata-rata tertinggi jawaban responden ditunjukkan pada pernyataan "Merek McDonald's mudah diingat dan sudah mendunia" dengan nilai rata - rata 4.40. selanjutnya nilai rata-rata terendah jawaban responden ditunjukkan pada pernyataan "McDonald's memiliki keunikan rasa yang berbeda dari restoran cepat saji lainnya” dengan nilai rata-rata sebesar 4.26.

\section{Tabel 12.Jawaban Responden mengenai Citra Merek}

\begin{tabular}{|c|c|c|c|c|c|c|c|}
\hline \multirow[b]{2}{*}{ Pernyataan } & \multicolumn{5}{|c|}{ Distribusi jawaban } & \multirow[b]{2}{*}{$\begin{array}{c}\text { Rata- } \\
\text { rata }\end{array}$} & \multirow[b]{2}{*}{ kriteria } \\
\hline & 1 & 2 & 3 & 4 & 5 & & \\
\hline $\begin{array}{l}\text { Produk Mcdonald's memiliki varian yang } \\
\text { berbeda dengan restoran cepat saji lainnya. }\end{array}$ & 2 & 4 & & 45 & 49 & 4.35 & $\begin{array}{c}\text { Sangat } \\
\text { baik }\end{array}$ \\
\hline $\begin{array}{l}\text { Merek McDonald's mudah diingat dan } \\
\text { sudah mendunia. }\end{array}$ & 2 & 2 & 1 & 44 & 51 & 4.40 & $\begin{array}{c}\text { Sangat } \\
\text { baik }\end{array}$ \\
\hline $\begin{array}{l}\text { McDonald's memiliki keunikan rasa yang } \\
\text { berbeda dari restoran cepat saji lainnya }\end{array}$ & 2 & 5 & & 51 & 42 & 4.26 & $\begin{array}{c}\text { Sangat } \\
\text { baik }\end{array}$ \\
\hline Rata - rata & & & & & & 4.33 & $\begin{array}{c}\text { Sangat } \\
\text { Baik }\end{array}$ \\
\hline
\end{tabular}

Sumber : Data primer yang diolah, 2020

Data pada Tabel 13, menunjukkan bahwa jawaban responden mengenai loyalitas pelanggan memperoleh nilai rata-rata sebesar 4.21 dan masuk dalam kriteria sangat tinggi. Hal tersebut 
menunjukkan bahwa loyalitas pelanggan di McDonald's sangat baik. Nilai rata-rata tertinggi jawaban responden ditunjukkan pada pernyataan "McDonals's adalah restoran cepat saji yang terbaik" sebesar 4.51. selanjutnya nilai rata-rata terendah jawaban responden ditunjukkan pada pernyataan "Saya tidak akan terpengaruh produk restoran cepat saji yang lain selain yang di tawarkan McDonald's sebesar 4.08

\section{Tabel 13 Jawaban Responden mengenai Loyalitas Pelanggan}

\begin{tabular}{|c|c|c|c|c|c|c|c|}
\hline \multirow{3}{*}{ Pernyataan } & \multirow{2}{*}{\multicolumn{5}{|c|}{ Distribusi jawaban }} & \multirow{3}{*}{ Rata-rata } & \multirow{3}{*}{ Kriteria } \\
\hline & & & & & & & \\
\hline & 1 & 2 & 3 & 4 & 5 & & \\
\hline $\begin{array}{l}\text { Saya selalu rutin membeli produk di } \\
\text { McDonald's. }\end{array}$ & & 7 & 4 & 48 & 41 & 4.23 & $\begin{array}{c}\text { Sangat } \\
\text { tinggi }\end{array}$ \\
\hline $\begin{array}{l}\text { Saya akan mengatakan hal yang positif } \\
\text { tentang McDonald's kepada orang lain. }\end{array}$ & 1 & 2 & 14 & 45 & 38 & 4.17 & Tinggi \\
\hline $\begin{array}{l}\text { Saya tidak akan terpengaruh produk } \\
\text { restoran cepat saji yang lain selain yang di } \\
\text { tawarkan McDonald's. }\end{array}$ & & 9 & 12 & 41 & 38 & 4.08 & Tinggi \\
\hline $\begin{array}{l}\text { Saya akan merefrensikan kualitas produk } \\
\text { McDonald's kepada orang lain yang belum } \\
\text { pernah membeli }\end{array}$ & 2 & 3 & 11 & 51 & 33 & 4.10 & Tinggi \\
\hline $\begin{array}{l}\text { McDonals's adalah restoran cepat saji yang } \\
\text { terbaik }\end{array}$ & & 2 & 5 & 33 & 60 & 4.51 & $\begin{array}{c}\text { Sangat } \\
\text { tinggi }\end{array}$ \\
\hline Rata-rata & & & & & & 4.21 & $\begin{array}{l}\text { Sangat } \\
\text { tinggi }\end{array}$ \\
\hline
\end{tabular}

Sumber : Data primer yang diolah, 2020

\section{Uji Asumsi Klasik}

\section{Uji Normalitas}

Hasil analisis regresi linier dengan grafik normal P-P Plot terhadap residual error model regresi diperoleh sudah menunjukkan adanya pola grafik yang normal, yaitu adanya sebaran titik yang berada tidak jauh dari garis diagonal. Hasil pengujian pada Gambar 2 menunjukkan bahwa titik-titik berada tidak jauh dari garis diagonal. Hal ini berarti bahwa model regresi tersebut sudah berdistribusi normal. 


\section{Gambar 4.2}

\section{Pengujian Normalitas}

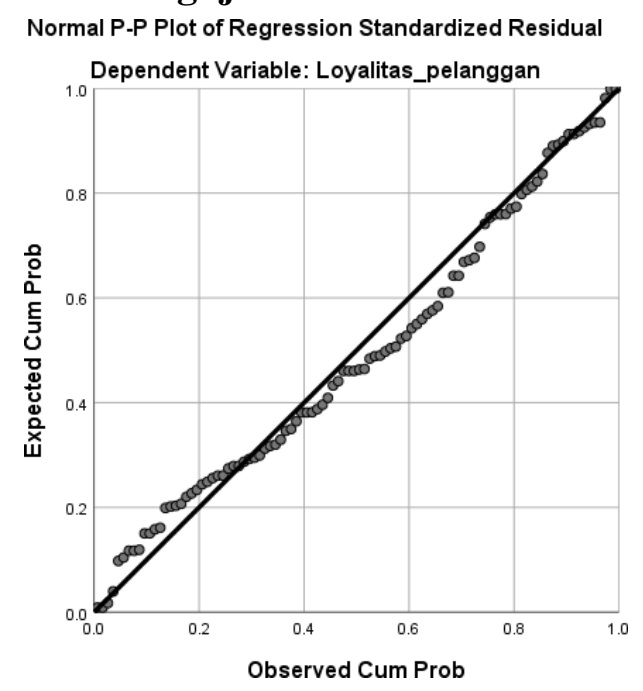

\section{Uji Multikolinearitas}

Pengujian multikolonieritas dilakukan dengan menggunakan nilai VIF.Suatu variabel menunjukkan gejala multikolonieritas bisa dilihat dari nilai VIF (Variance Inflation Factor) yang tinggi pada variabel-variabel bebas suatu model regresi. Nilai VIF dari variabel bebas pada model regresi dapat dilihat pada Tabel 14 di mana hasil pengujian menunjukkan nilai VIF dari semua variabel bebas memiliki nilai yang lebih kecil dari 10.Hal ini berarti bahwa variabel - variabel penelitian tidak menunjukkan adanya gejala multikolenearitas dalam model regresi.

Tabel 14 Hasil Pengujian Multikolinearitas

\begin{tabular}{ccc}
\hline Variabel & VIF & Tolerance \\
\hline Kualitas Pelayanan & 1.541 & 0.649 \\
Bauran Pemasaran & 1.551 & 0.645 \\
Citra Merek & 1.047 & 0.955 \\
\hline
\end{tabular}

Sumber : data primer, diolah (2020) 


\section{Uji Heteroskedastisitas}

Model regresi yang baik adalah tidak terjadi heterokedastisitas. Untuk mengetahui ada tidaknya gejala heteroskedastisitas dapat dilakukan dengan menggunakan grafik heteroskedastisitas antara nilai prediksi variabel dependen dengan variabel indepeden.

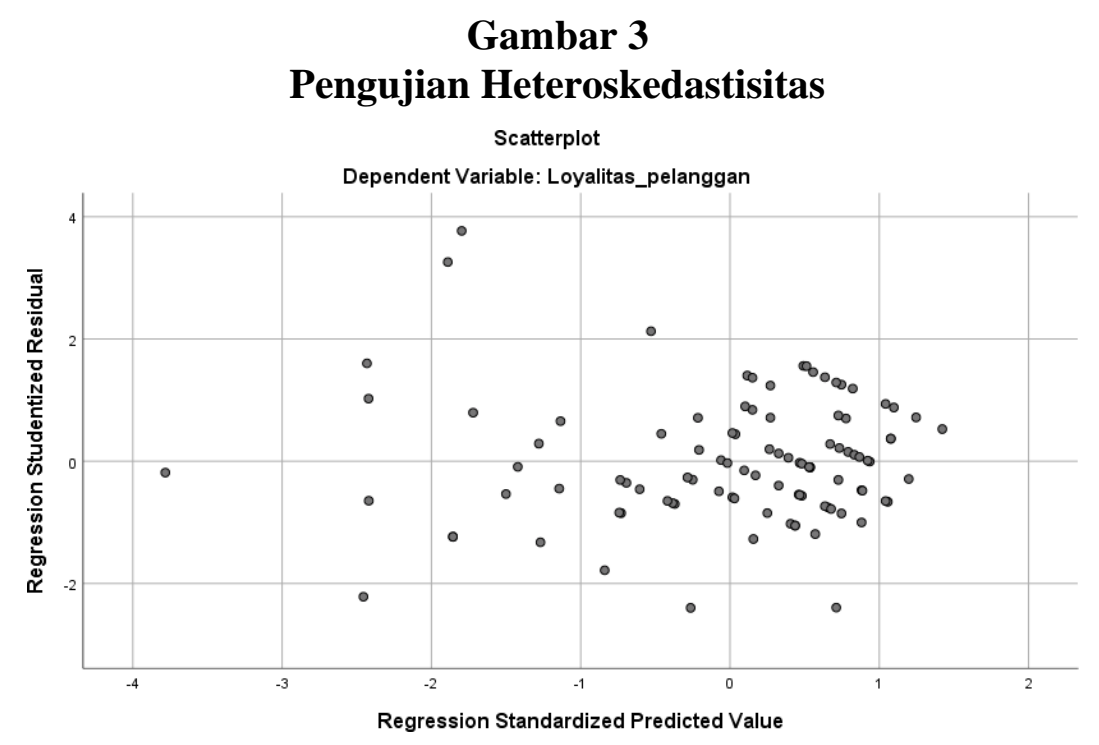

Dari scatterplots pada Gambar 3 terlihat titik - titik menyebar secara acak serta tersebar baik diatas maupun dibawah angka 0 dan sumbu $\mathrm{Y}$, hal ini dapat disimpulkan bahwa tidak terjadi heteroskedastisitas pada model regresi, sehingga model regresi layak untuk digunakan dalam melakukan pengujian.

\section{Analisis Regresi Linear Berganda}

untuk menjawab hipotesis yangtelah diajukan, baik hipotesis parsial maupun simultan maka digunakan teknik analisis data berupta regresi linear berganda yang hasilnya dapat dilihat pada Tabel 15 .

\section{Tabel 15}




\section{Hasil uji Regresi linear Berganda}

\begin{tabular}{|c|c|c|c|c|c|}
\hline \multirow[b]{2}{*}{ Model } & \multicolumn{2}{|c|}{$\begin{array}{c}\text { Unstandardized } \\
\text { Coefficients }\end{array}$} & \multirow{2}{*}{$\begin{array}{c}\text { Standardize d } \\
\text { Coefficients } \\
\text { Beta }\end{array}$} & \multirow[b]{2}{*}{$\mathrm{t}$} & \multirow[b]{2}{*}{ Sig. } \\
\hline & B & Std. Error & & & \\
\hline (Constant) & 2.167 & 2.085 & & 1.039 & .301 \\
\hline Kualitas_pelayanan & .432 & .072 & .516 & 6.015 & .000 \\
\hline Bauran_pemasaran & .318 & .087 & .314 & 3.654 & .000 \\
\hline Citra_Merek & .360 & .101 & .251 & 3.557 & .001 \\
\hline
\end{tabular}

Sumber : data primer, diolah (2020)

Dari tabel 4.15 diatas diperoleh persamaan sebagai berikut :

$\mathrm{Y}=\mathrm{a}+\mathrm{b} 1 \mathrm{X} 1+\mathrm{b} 2 \mathrm{X} 2+\mathrm{b} 3 \mathrm{X} 3$, maka menjadi :

$Y=2.167+0.432+0.318+0.360$

Persamaan regresi tersebut dapat dijelaskan sebagai berikut :

a. $\mathrm{a}=2.167$, artinya apabila kualitas pelayanan, bauran pemasaran dan citra merek dianggap nol maka tingkat loyalitas pelanggan adalah sebesar rata-rata 2.167.

b. $b_{1} X_{1}=0.432$, artinya apabila kualitas pelayanan meningkat sebesar satu-satuan akan diikuti oleh meningkatnya tingkat loyalitas pelanggan sebesar 0.432 .

c. $b_{2} X_{2}=0.318$, artinya apabila bauran pemasaran meningkat sebesar satu- satuan akan diikuti dengan meningkatnya loyalitas pelanggan sebesar 0.318 .

d. $\quad b_{3} X_{3}=0.360$, artinya apabila citra merek meningkat sebesar satu-satuan akan diikuti dengan meningkatnya loyalitas pelanggan sebesar 0.318 .

\section{Analisis Determinasi}

Pada Tabel 16, kolom R Square dapat dilihat bahwa koefisien determinasi sebesar 0.542 atau $54.2 \%$ yang artinya variasi hubungan antara kualitas pelayanan, bauran pemasaran dan citra merek terhadap loyalitas pelanggan adalah sebesar 54.2\% sedangkan sisanya $45.8 \%$ ditentukan oleh variabel lain di luar kualitas pelayanan, bauran pemasaran dan citra merek yang tidak dibahas dalam penelitian ini. 


\section{Hasil Uji Analisis Koefisien Determinasi \\ Model Summary}

\begin{tabular}{|lr|r|r|r|r|}
\hline Model & R & R Square & $\begin{array}{c}\text { Adjusted R } \\
\text { Square }\end{array}$ & $\begin{array}{l}\text { Std. Error of } \\
\text { the Estimate }\end{array}$ & $\begin{array}{l}\text { Durbin- } \\
\text { Watson }\end{array}$ \\
\hline 1 & $.736^{\mathrm{a}}$ & .542 & .527 & 1.918 & 1.572 \\
\hline
\end{tabular}

Sumber : data diolah, 2020.

\section{Uji Signifikansi Parsial (t-test)}

Uji ini dilakukan untuk menjawab hipotesis 1, 2, dan 3 yangtelah diajukan sebelumnya. Untuk menjawab hipotesis tersebut, maka hasil uji dapat dilihat pada Tabel 16. Dari tabel 16 maka dapat dikemukakan hasil sebagai berikut :

\section{Tabel 16}

\section{Hasil Uji t-tes}

\begin{tabular}{|c|c|c|c|c|c|}
\hline \multirow[b]{2}{*}{ Mode1 } & \multicolumn{2}{|c|}{$\begin{array}{l}\text { Unstandardized } \\
\text { Coefficients }\end{array}$} & \multirow{2}{*}{$\begin{array}{c}\text { Standardize d } \\
\text { Coefficients } \\
\text { Beta }\end{array}$} & \multirow[b]{2}{*}{$\mathbf{t}$} & \multirow[b]{2}{*}{ Sig. } \\
\hline & B & Std. Error & & & \\
\hline (Constant) & 2.167 & 2.085 & & 1.039 & .301 \\
\hline Kualitas_pelayanan & .432 & .072 & .516 & 6.015 & .000 \\
\hline Bauran_pemasaran & .318 & .087 & .314 & 3.654 & .000 \\
\hline Citra_Merek & .360 & .101 & .251 & 3.557 & .001 \\
\hline
\end{tabular}

Sumber : data diolah, 2020

1. Pengaruh kualitas pelayanan terhadap loyalitas pelanggan. Hasil pengujian t-test untuk kualitas pelayanan dapat dilihat pada tabel 16 pada kolom $t$, bahwa nilai $t_{\text {hitung }}(6.015)>$ $\mathrm{t}_{\text {tabel }}(1,66)$ dan signifikansi $0,000<0,05$ maka $\mathrm{H} 1$ diterima yang berarti kualitas pelayanan secara parsial berpengaruh signifikan terhadap loyalitas pelanggan. Hasil ini mendukung penelitian yang dilakukan oleh Andy Tendri (2015), Abdul Muzammil (2017), Dhisma Chrismastuty (2017), Amelia Septian (2019), dan Karina Hartono (2013) yang telah membuktikan kualitas pelayanan berpengaruh positif dan signifikan terhadap loyalitas pelanggan. 
2. Pengaruh bauran pemasaran terhadap loyalitas pelanggan. Hasil pengujian t-test untuk citra merek dapat dilihat pada Tabel 16 pada kolom $t$, bahwa nilai $t_{\text {hitung }}(3.654)>t_{\text {tabel }}$ (1.66) dan nilai signifikansi $0,000<0,05$ maka $\mathrm{H} 2$ diterima yang berarti bauran pemasaran secara parsial berpengaruh signifikan terhadap loyalitas pelanggan. Hasil ini mendukung hasil penelitian yang dilakukan Gede Hardy dan Suprapti (2017), Edy Winata (2015), dan Yusriadi (2018).

3. Pengaruh citra merek terhadap loyalitas pelanggan. Hasil pengujian t-test untuk citra merek dapat dilihat pada tabel 16 pada kolom $t$, bahwa nilai $t_{\text {hitung }}(3.557)>t_{\text {tabel }}(1.66)$ dansignifikansi $0,001<0,05$ maka $\mathrm{H} 3$ yang berarti citra merek secara parsial berpengaruh signifikan terhadap loyalitas pelanggan. Jadi dapat disimpulkan bahwa hipotesis ketiga $\left(\mathrm{H}_{3}\right)$ diterima. Hasil ini mendukung penelitian yang dilakukan oleh Abdul Muzammil dkk (2017), Dhisma Chrismastuty (2017), Amelia Septian (2019), Elinawati dkk (2017) yang membuktikan citra merek berpengaruh positif dansignifikan terhadap loyalitas pelanggan

\section{Uji Signifikansi F-test}

Uji ini digunakan untuk mengetahui apakah variabel independen $\left(\mathrm{X}_{1}, \mathrm{X}_{2}\right.$ dan $\left.\mathrm{X}_{3}\right)$ secara bersama-sama berpengaruh secara signifikan terhadap variabel dependen (Y). hasil uji F-tes dapat dilihat pada Tabel 17. Pada tabel 17 dapat dilihat pada kolom F, bahwa nilai F hitung sebesar 37.812 lebih besar dari F tabel yaitu 2.70. Karena F Hitung lebih besar, maka Ho ditolak sehingga dapat disimpulkan bahwa kualitas pelayanan $\left(\mathrm{X}_{1}\right)$, bauran pemasaran $\left(\mathrm{X}_{2}\right)$ dan citra merek $\left(\mathrm{X}_{3}\right)$ secara bersama - sama (simultan) berpengaruh positif terhadap loyalitas pelanggan (Y). Jadi dapat disimpulkan bahwa hipotesis keempat $\left(\mathrm{H}_{4}\right)$ diterima. 


\section{Tabel 17
Hasil Uji Signifikansi F-test}

\begin{tabular}{|c|c|c|c|c|c|c|}
\hline \multirow[b]{2}{*}{ Mode } & \multicolumn{6}{|c|}{ Anova } \\
\hline & & $\begin{array}{l}\text { Sum of } \\
\text { Squares }\end{array}$ & Df & $\begin{array}{l}\text { Mean } \\
\text { Square }\end{array}$ & $\mathrm{F}$ & Sig. \\
\hline \multirow[t]{3}{*}{1} & Regression & 417.156 & 3 & 139.052 & 37.812 & $.000^{\mathrm{b}}$ \\
\hline & Residual & 353.034 & 96 & 3.677 & & \\
\hline & Total & 770.190 & 99 & & & \\
\hline
\end{tabular}

Sumber : data diolah, 2020.

\section{SIMPULAN}

\section{Simpulan}

Berdasarkan hasil analisis penelitian dan hasil pembahasan pada bab sebelumnya, maka dapat disimpulkan sebagai berikut :

1. Kualitas pelayanan berpengaruh positif dan signifikan terhadap loyalitas pelanggan. Hal ini dapat dibuktikan melalui hasil uji t yang diperoleh yaitu nilai thitung sebesar 6.015 lebih besar dari tabel yaitu 1.66071. Karena thitung lebih besar, maka H0 ditolak dan H1 diterima. Hal ini berarti semakin baik kualitas pelayanan yang diberikan McDonald's akan semakin meningkatkan loyalitas pelanggan McDonald's. Bauran pemasaran berpengaruh positif dan signifikan terhadap loyalitas pelanggan. Hal ini dapat dibuktikan melalui hasil uji t yang diperoleh yaitu nilai thitung sebesar 3.654 lebih besar dari $t_{\text {tabel }}$ yaitu 1.66071. Karena thitung lebih besar, maka H0 ditolak dan $\mathrm{H} 2$ diterima. Hal ini berarti semakin baik bauran pemasaran yang diberikan McDonald's akan semakin meningkatkan loyalitas pelanggan McDonald's.

2. Bauran pemasaran berpengaruh positif dan signifikan terhadap loyalitas pelanggan. Hal ini dapat dibuktikan melalui hasil uji t yang diperoleh yaitu nilai $t_{\text {hitung }}$ sebesar 3.654 lebih besar dari $t_{\text {tabel }}$ yaitu 1.66071. Karena thitung lebih besar, maka H0 ditolak dan H2 diterima. Hal ini berarti semakin baik bauran pemasaran yang diberikan McDonald's akan semakin meningkatkan loyalitas pelanggan McDonald's.

3. Citra Merek berpengaruh positif dan signifikan terhadap loyalitas pelanggan. Hal ini dapat dibuktikan melalui hasil uji t yang diperoleh yaitu nilai thitung sebesar 3.557 lebih besar dari tabel yaitu 1.66071. Karena thitung lebih besar, maka H0 ditolak dan H3 diterima. Hal ini berarti semakin baik citra merek yang diberikan McDonald's akan 
semakin meningkatkan loyalitas pelanggan McDonald's..

4. Kualitas pelayanan, bauran pemasaran dan citra merek berpengaruh positif dan signifikan terhadap loyalitas pelanggan. Hal ini dibuktikan dengan hasil uji $\mathrm{F}$ yang diperoleh yaitu nilai $F_{\text {hitung }}$ sebesar 37.812 lebih besar dari $F_{\text {tabel }}$ yaitu 2.70 . Karena $F_{\text {hitung }}$ lebih besar, maka H0 ditolak dan H4 diterima. Hal ini berarti semakin baik kualitas pelayanan, bauran pemasaran dan citra merek yang diberikan McDonald's akan semakin meningkatkan loyalitas pelanggan McDonald's

Berdasarkan hasil analisis penelitian, pembahasan dan kesimpulan terdapat beberapa saran yang dapat diberikan peneliti sebagai berikut, antara lain :

1. Dari pernyataan mengenai kualias pelayanan, pernyataan Karyawan McDonald's cepat membantu pelanggan McDonald's dalam memberikan pelayanan memiliki nilai rata rata terendah, melihat hasil penelitian tersebut McDonald's hendaknya memberikan pelatihan kepada karyawan dalam melayani pelanggan sesuai dengan SOP dan melakukan refreshment setiap bulan.

2. Dari pernyataan mengenai bauran pemasaran, pernyataan Mcdonald's sering memberikan promo bagi pelanggannya memiliki nilai rata - rata terendah, melihat hasil penelitian tersebut McDonald's hendaknya memberikan promo - promo menarik untuk meningkatkan minat pelanggan untuk melakukan pembelian produk kembali.

3. Dari pernyataan mengenai citra merek, McDonald's memiliki keunikan rasa yang berbeda dari restoran cepat saji lainnya memiliki nilai rata - rata terendah, melihat hasil penelitian tersebut McDonald's hendaknya melakukan inovasi rasa yang mampu memberikan cita rasa yang berbeda di lidah para pelanggannya sehingga mampu menyaingi kompetitor.

4. Dari pernyataan mengenai loyalitas, saya tidak akan terpengaruh produk restoran cepat saji yang lain selain yang di tawarkan McDonald's memiliki nilai rata - rata terendah, melihat hasil penelitian tersebut McDonald's hendaknya selalu memperhatikan setiap pelanggannya dengan meningkatkan kualitas pelayanan, berinovasi pada produk dan mau menerima masukan dari pelanggan. Sehingga pelanggan tetap setia terhadap produk yang dihasilkan.

5. Bagi peneliti selanjutnya, agar dapat meneliti dan mengkaji lebih dalam faktor-faktor lain yang tidak diteliti dalam penelitian ini yang dapat mempengaruhi loyalitas pelanggan di McDonald's selain kualitas pelayanan, bauran pemasaran dan citra produk, 
agar kedepannya dapat mengetahui tindakan apa yang harus dilakukan oleh McDonald's agar pelanggan tetap loyal.

\section{REFERENSI}

Abdul Muzammil, Mukhlis Yunus, dan Nurdasila Darsono (2017). Pengaruh Kualitas Pelayanan Dan Citra Perusahaan Terhadap Loyalitas Pelanggan Indihome PT. Telkom Indonesia Di Banda Aceh Dengan Kepuasan Dan Kepercayaan Pelanggan Sebagai Variabel Mediasi.Jurnal Program Studi Magister Manajemen Fakultas Ekonomi dan Bisnis Universitas Syiah Kuala.

Amelia Septian Aryamti dan AMA Suyanto (2019).Analisis Kualitas Produk, Kualitas Pelayanan Dan Citra Merek Pada Kepuasan Pelanggan Klinik Kecantikan Dan Pengaruhnya Terhadap Loyalitas Pelanggan.Prodi S1 MBTI, Fakultas Ekonomi dan Bisnis, Universitas Telkom.

Andy Tendri Sompa, Emi Suwarni, Muji Gunarto.(2015). Kualitas Pelayanan Dan Harga Terhadap Loyalitas Konsumen Cepat Saji Di Kota Palembang (Studi Pada Kentucky Fried Chicken (KFC). Jurnal Program Studi Manajemen Universitas Bina Dharma.

Desi Ambar Ayu (2017). Pengaruh Kualitas Pelayanan, Promosi, Dan Citra Merek Terhadap Loyalitas Pelanggan Im3.Fakultas Ekonomi UN PGRI Kediri

Dhisma Chrismastuty, Rahayu Triastity, dan Lamidi (2017).Pengaruh Kualitas Pelayanan Dan Citra Perusahaan Terhadap Loyalitas Pelanggan Dengan Kepuasan Pelanggan Sebagai Variabel Mediasi (Survei Pada Pelanggan Di Salon Mobil M2cw Karanganyar). Program Studi Manajemen Fakultas Ekonomi Universitas Slamet Riyadi Surakarta.

Edy Winata(2015).Pengaruh Bauran Pemasaran Jasa Terhadap Loyalitas Konsumen Pada Grand Serela Hotel \& Convention Medan.Jurnal Dosen Program Studi Manajemen Sekolah Tinggi Ilmu Manajemen Sukma.

Elinawati Susi Mentari Sinurat, Bode Lumanauw, dan Ferdy Roring.(2017). Pengaruh Inovasi Produk, Harga, Citra Merek Dan Kualitas Pelayanan Terhadap Loyalitas Pelanggan Mobil Suzuki Ertiga.Manajemen Fakultas Ekonomi dan Bisnis Universitas Sam Ratulangi Manado.

Gede Hadi Reynaldidan Ni Wayan Sri Suprapti.(2017). Pengaruh Bauran Pemasaran Terhadap Loyalitas Pelanggan Mobil Merek „Honda" Di Kota Denpasar. Jurnal Program Studi Ekonomi dan Bisnis Universitas Udayana (Unud) Vol. 6 No. 1, 2017 hal: $375-401$

Karina Hartono (2013). Pengaruh Kualitas Layanan Terhadap Kepuasan Pelanggan Dalam Membentuk Loyalitas Pelanggan Mcdonald"s Basuki Rahmat Surabaya.Manajemen/Fakultas Bisnis dan Ekonomika Universitas Surabaya. 
Yusriadi (2018).Pengaruh Bauran Pemasaran (Marketing Mix) Terhadap Loyalitas Konsumen Pada Restoran Cepat Saji O"chicken Di Pekanbaru.Sekolah Tinggi Ilmu Ekonomi Riau. 